\title{
O artesanal e o mecânico
} na série Silhuetas e Fantasmagorias de Manuela Siebert

The handmade and the mechanic in the Silhouettes and Phantasmagorias series by Manuela Siebert

\section{Wagner Jonasson da Costa Lima ${ }^{1}$}

1 Professor colaborador da Universidade Estadual do Paraná - UNESPAR. Possui Doutorado e Mestrado em Artes Visuais pelo Programa de Pós-graduação do Centro de Artes da Universidade do Estado de Santa Catarina - UDESC e graduação em Superior de Pintura pela Escola de Música e Belas Artes do Paraná - EMBAP. Lattes: http://lattes.cnpq.br/6387421009827388

E-mail: wagnerjonasson@hotmail.com 


\title{
Resumo
}

O texto aborda a relação estabelecida entre pintura e imagem técnica na produção da artista catarinense Manuela Siebert, procurando investigar como essa associação interferiu no processo de elaboração e na visualidade de seus trabalhos. Para tanto, considera a fatura de determinadas pinturas da série intitulada Silhuetas e Fantasmagorias. Nesse conjunto de telas, a artista procurou conferir à pintura um aspecto semelhante à da imagem mecanicamente impressa, adotando, para esse fim, técnicas e materiais pertencentes à esfera do design e da comunicação visual. Com isso, Manuela incorporou, no interior da sua prática pictórica, uma lógica próxima ao do modo de produção industrial, assinalado pela divisão entre projeto e execução. Realizadas em estágios pré-determinados, as pinturas da série exibem contornos e cores que lembram a superfície impessoal e estandardizada das imagens veiculadas pelos meios de comunicação de massa.

\section{Palavras-chave}

Manuela Siebert; pintura; imagem técnica.

\begin{abstract}
This text approaches the relation established between painting and technical image in Manuela Siebert's production, investigating how such association interfered over the elaboration process and visuality of her works. Thus, it takes into account the making of certain paintings from Silhuetas e Fantasmagorias series. In this set of canvas, the artist conferred to the paintings an aspect similar to mechanically-printed image, adopting techniques and materials of design and visual communication's field to achieve such end. Thereby, Manuela incorporated in her pictorial practice a logic close to the industrial production mode, characterized by division between project and manufacturing. Executed at pre-determined stages, the paintings show outlines and colors which remind the impersonal and standardized images disseminated by mass media.
\end{abstract}

\section{Keywords}

Manuela Siebert; painting; technical image.

ISSN: 2447-1267 


\section{Introdução}

Desde o advento da fotografia, a primeira imagem técnica, um novo paradigma de produção de imagem foi introduzido, impactando as artes tradicionais. Nas primeiras décadas do século XX, por exemplo, a fotografia instantânea, desenvolvida por Étienne-Jules Marey (1830-1904) e Eadweard Muybridge (1830-1904), atraiu a atenção de artistas como Marcel Duchamp (1887-1968). Em Nu descendant un escalier $n^{\circ} 2$, pintura realizada em 1912, Duchamp buscou "uma imagem estática do movimento" (DUCHAMP apud CABANNE, 2002, p. 50), estabelecendo uma clara relação com a cronofotografia, técnica fotográfica voltada para o registro de um corpo em movimento. Nas décadas seguintes, após renunciar à arte "retiniana" em favor do ready-made, termo que cunhou para objetos industriais deslocados para os espaços expositivos da arte, Duchamp envolveu-se diretamente com a fotografia e com o cinema. Nessa trajetória, é possível observar como o artista extraiu do meio fotográfico as possibilidades de renovação de seus procedimentos (KRAUSS, 2013).

Na década de 1960, a arte pop tratou de incorporar definitivamente ao repertório da pintura imagens provenientes dos meios de comunicação de massa. No caso de Andy Warhol (1928-1987), fotografias de grande circulação foram adquiridas, fotografadas novamente e transpostas para a superfície da tela por meio da técnica da serigrafia. Suprimindo os vestígios de um fazer expressivo, ainda presente na produção de Robert Rauschenberg (1925-2008) e Jasper Johns (1930-), pinturas como Marilyn Diptych (1962) e Orange Car Crash Fourteen Times (1963) oferecem uma superfície "com cores muitas vezes extravagantes, que só fazem sublinhar o caráter segundo dos ícones selecionados" (FABRIS, 2009, p. 143). Nesses trabalhos também se encontra a repetição de imagens, recurso que, explorado de maneira espetacular pelo artista norte-americano, rebate a ideologia do novo e anuncia outro entendimento de sujeito. Instalado em sua Factory, misto de ateliê e linha de produção, Warhol declarou: "Quero ser uma máquina".

Essa atitude niveladora de Warhol, assinalada pela indiferenciação entre "cultura erudita" e "cultura de massas", entre o artesanal e o mecânico, também distinguiu a chamada "arte da apropriação". O termo foi associado a determinados artistas norte-americanos que iniciaram as suas atividades no final da década de 1970 e início da seguinte, sobretudo Sherrie Levine (1947-) e aqueles reunidos sob o rótulo de "simulacionistas", como Peter Halley (1953-), Jeff Koons (1955-) e Ashley Bickerton (1959-). Mantendo em suspenso noções de autoria e originalidade, esses artistas procuraram, na visão de Harrison e Wood (2001, p. 241), "elevar os produtos da cultura popular e do desenho industrial aos contextos artísticos, com vistas a subverter a autoridade da arte". Nessa produção, que abrange fotografia, pintura e escultura, tornou-se recorrente a transgressão à separação categórica, estabelecida pela teoria da arte modernista, entre "vanguarda" e "kitsch", entre "arte" e "cultura".

É possível identificar na produção de Manuela Siebert, artista natural de Santa Catarina, esse estreito diálogo entre a pintura e a imagem técnica, a "imagem produzida por aparelhos" (FLUSSER, 1985, p. 19), que assinalou os trabalhos de Duchamp, de 
Warhol e dos "apropriacionistas" ou "simulacionistas" da década de 1980. Na série intitulada Silhuetas e Fantasmagorias, que reúne doze trabalhos, a artista procurou conferir à pintura um aspecto semelhante à da imagem mecanicamente impressa, adotando, para esse fim, técnicas e materiais pertencentes à esfera do design e da comunicação visual. Com essa postura, Manuela acabou por introduzir, no cerne de sua poética, a lógica do modo de produção industrial, assinalado pela divisão entre projeto e execução. Dessa maneira, as telas da artista, realizadas em etapas determinadas de antemão, apresentam contornos e cores que correspondem à superfície indiferente e uniforme das imagens difundidas pelos meios de comunicação de massa.

Com o objetivo de analisar como a associação entre a pintura e a imagem técnica interferiu no processo de elaboração e na visualidade dos trabalhos de Manuela, o texto considera a fatura de determinados quadros da série Silhuetas e Fantasmagorias. As pinturas foram expostas pela primeira vez em novembro de 2015, nas dependências do Museu da Escola Catarinense (MESC), instituição vinculada à Universidade do Estado de Santa Catarina (UDESC). Naquela ocasião, a artista concluía o seu Trabalho de Conclusão de Curso, intitulado Silhuetas e Fantasmagorias: entre pintura e imagem técnica, cuja defesa foi acompanhada pela exibição, em uma das salas do Museu, do conjunto de trabalhos resultantes da pesquisa.

\section{Das silhuetas às fantasmagorias}

Em 2012, ainda como aluna do Curso de Artes Visuais da Universidade do Estado de Santa Catarina (UDESC), Manuela Siebert iniciou uma série de pinturas de pequenas dimensões que exibem elementos que se tornarão recorrentes em sua produção. No trabalho intitulado Eyeshadow (Figura 1), por exemplo, figuras planas e pretas, que lembram pequenos estojos de maquiagem com abas abertas e espelhos reluzentes, contrastam com uma superfície de amarelo intenso. Esquemática e chamativa, a pintura, realizada com a técnica do guache sobre papel, guarda semelhanças com folders e cartazes publicitários. Ao mesmo tempo, as figuras dos estojos, devido a sua ausência de modelado e a sua disposição no espaço pictórico, convertem-se em lápides soltas sobre um espaço indefinido. Assim, objetos associados ao universo dos artigos de beleza comparecem como lembranças do efêmero e da morte, em uma atmosfera simbólica próxima àquela encontrada nas vanitas do século XVII.

Esse caráter ambivalente presente na pintura de Manuela, a meio caminho entre as imagens dos meios de comunicação de massa e as imagens da história da arte, decorre, em grande parte, do seu modo de produção, calcado na técnica da silhueta e, por conseguinte, nas diversas funções e significados a ela atribuídos. Desde o século XIX, a expressão "silhueta", derivada do nome do ministro das finanças de Luís $\mathrm{XV}$, Étienne de Silhouette (1709-1767), refere-se a um contorno ou a um perfil obtido a partir da sombra projetada de uma pessoa ou de um objeto. Com o advento da arte moderna, o processo de silhuetagem, que elimina detalhes e enfatiza contornos, 
simplificando a representação, tornou-se atraente devido à sua distância do ilusionismo da pintura naturalista. Também naquele momento, no interior do nascente discurso das artes aplicadas e do design, a silhueta começou a ser vista como um meio apropriado para a publicidade, que estava surgindo no início do século XX (COWAN, 2013).

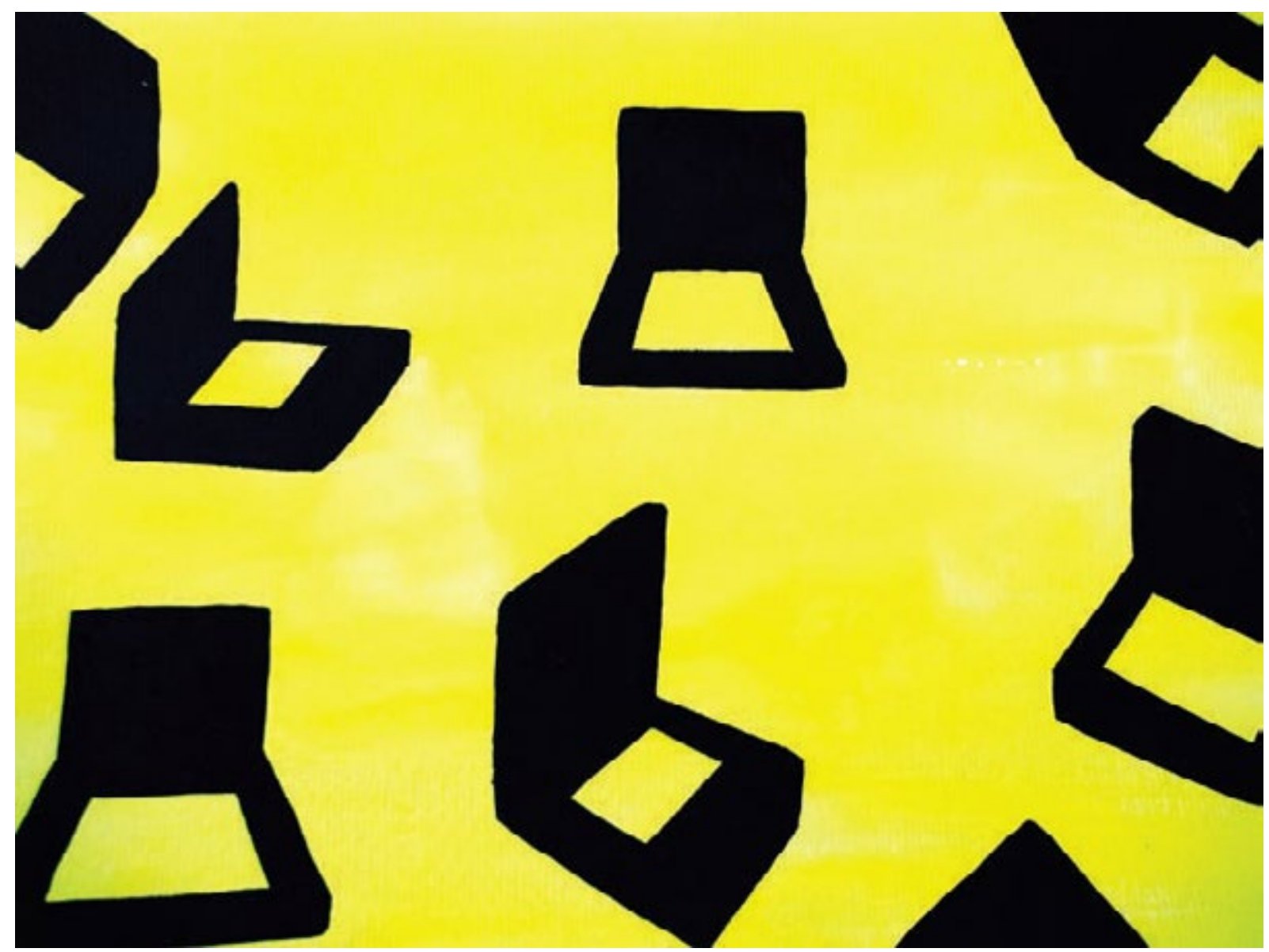

Fig. 1. Manuela Siebert, Eyeshadow, 2012, guache sobre papel. Fonte: Acervo da artista.

Levando adiante o potencial plástico e simbólico da silhueta, já explorado no trabalho Eyeshadow, Manuela iniciou, em meados de 2014, outro conjunto de pinturas, mais tarde intitulado Silhuetas e Fantasmagorias (SIEBERT, 2015). Para realizar essa nova série, a artista, em um primeiro momento, apropriou-se de silhuetas femininas preexistentes, que encontrou em sites de busca da Web, subvertendo as suas poses por meio da manipulação digital. Nessa etapa de elaboração, Manuela dispensou qualquer material usualmente associado ao ofício do pintor, como pincéis e tubos de tinta, adotando ferramentas disponíveis em programas de edição de imagens. No computador, as silhuetas femininas foram retrabalhadas por meio de inversões, de espelhamentos ou reunidas com outras partes de figuras, adquirindo novas configurações e novos sentidos. Como no procedimento alegórico, discutido por autores como Walter Benjamin (1984) e Craig Owens (2004), imagens são geradas a partir de outras, em uma corrente perpétua.

Voltada para a desconstrução e reconstrução, a manipulação de imagens realizada 
por Manuela exibe pontos de contato com a fotomontagem, técnica considerada com frequência como o "umbral da arte contemporânea" (FLORES, 2011, p. 188). O termo "fotomontagem", segundo Dawn Ades (2002), foi concebido no momento em que os dadaístas de Berlim sentiram a necessidade de um nome para designar a introdução de fotografias em sua produção. Lançando mão de figuras e tipografias provenientes dos meios de comunicação de massa, como revistas e jornais, artistas como Raoul Hausmann (1886-1971) e Hannah Höch (1889-1978) produziram trabalhos assinalados pela fragmentação e pela descontinuidade. Essa utilização da fotografia, como imagem ready-made, pode ser considerada como parte da reação do grupo à natureza "irrepetível, privada e exclusiva" (ADES, 2002, p. 13) da pintura a óleo. A fotomontagem, em contraste à unicidade da pintura, inseria-se em uma nova realidade tecnológica, reconhecida pela reprodução fotomecânica.

Entretanto, no seu processo de desmantelamento e reestruturação das silhuetas recolhidas na Web, Manuela Siebert não fez uso de tesoura e cola, como nas fotomontagens de Hausmann e Höch, mas de um programa de computador, beneficiando-se assim da maleabilidade da imagem digital. Diferente da imagem fotográfica, que depende da inscrição de raios luminosos emitidos por um objeto sobre um suporte sensível, a imagem digital resulta de interações matemáticas com um computador (SANTAELLA; NÖTH, 1998). Nesse modo de produção, valores numéricos, depois de alterados por modelos de visualização, são traduzidos em pontos elementares que viabilizam a exibição da imagem em uma tela de vídeo. Nesse sentido, Manuela, como diversos artistas que lidam com a imagem digital, não agiu sobre uma realidade física, mas sobre outro substrato, a informação. E toda a informação, especialmente aquela ligada ao universo da computação, é passível de uma quantidade considerável de manipulações e alterações.

Uma vez determinadas digitalmente, as silhuetas de Manuela foram transferidas para a tela com o auxílio de estênceis de vinil adesivo, todos obtidos mecanicamente, por meio de um plotter de recorte (SIEBERT, 2015). Máquina impressora comumente utilizada na área da comunicação visual, o plotter de recorte possui uma lâmina que permite o corte de diversos materiais, como papéis e plásticos, de acordo com o que foi elaborado previamente em um programa de computador. Para confeccionar os seus estênceis, a artista redimensionou as silhuetas construídas anteriormente, levando em consideração o tamanho dos suportes, que por vezes alcançam um metro de altura por dois metros de largura. Em seguida, inseriu uma grande folha de vinil adesivo na máquina impressora e acionou o comando para que o material fosse recortado. Depois de prontos, os estênceis foram fixados sobre a tela e receberam várias camadas de tinta. A operação foi repetida até a obtenção da imagem final, constituída de contornos nítidos e contidos.

Antes da pintura das silhuetas, porém, determinadas cores foram selecionadas para o fundo dos quadros e aplicadas com uma pistola de ar comprimido, técnica que possibilitou, juntamente com o emprego da tinta acrílica industrial, uma superfície de textura e de cor homogêneas (SIEBERT, 2015). Abrindo mão mais uma vez de materiais convencionais, Manuela adquiriu as suas tintas em lojas especializadas no 
comércio de materiais para pintura residencial e automotiva. As cores foram misturadas por uma máquina dispensadora no próprio ponto de venda, a partir de catálogos disponibilizados pelos fabricantes. Já em seu ateliê, munida de máscara e luvas, a artista despejou a tinta no reservatório da pistola de ar comprimido e pulverizou a superfície da tela com movimentos regulares. Nesse processo de pintura, tanto dos fundos quanto das silhuetas, Manuela manteve certa distância do suporte, postura que impediu qualquer gestualidade palpável.

Cabe lembrar, no entanto, que o emprego do estêncil e da pulverização não é exclusividade da artista catarinense. A partir de meados da década de 1950, por exemplo, Jasper Johns usou estênceis de números e de letras produzidos industrialmente na composição de pinturas como White Numbers (1957) e Fool's House (1962). Como observou o historiador e crítico de arte Leo Steinberg (2008, p. 56), Johns é o artista para quem "o tema pré-formado é uma condição da pintura". O estêncil também foi e prossegue sendo muito utilizado no grafite, manifestação artística que surgiu nos grandes centros urbanos no final da década de 1970 (LARA, 1996). Com ênfase em ícones encontrados nos meios de comunicação de massa, os grafites elaborados com máscaras, que são feitas com recortes vazados em acetato ou papelão, elegem como procedimento a apropriação e a repetição de imagens.

Quanto à pintura por pulverização, a técnica esteve em voga na Bauhaus, escola fundada pelo arquiteto alemão Walter Gropius (1883-1969), em 1919, com o intuito de "recompor entre a arte e a indústria produtiva o vínculo que unia a arte ao artesanato" (ARGAN, 1992, p. 269). Na Bauhaus da cidade de Dessau, onde se oferecia a Oficina de Pintura Mural, extensas superfícies eram cobertas com o auxílio de pistolas acionadas por compressores produzidos pela indústria automotiva (GAGE, 2012). Já nas décadas de 1960 e 1970, a pulverização podia ser encontrada na produção de artistas associados ao chamado Hiper-realismo. Pintores como Chuck Close (1940-) utilizaram repetidamente o aerógrafo, outro tipo de pistola de ar comprimido que proporciona a aplicação de camadas finas de tinta e gradações sutis de claro-escuro. Fria e objetiva, distante da fatura heroica da action painting (ROSENBERG, 1974), a técnica abraçada pelos hiper-realistas baseava-se na lógica do registro fotográfico (FABRIS, 2013).

Em vista disso, Manuela Siebert, ao adotar o estêncil e a pulverização na realização de suas pinturas, aproximou-se de uma corrente de artistas que, no transcorrer do século XX, buscaram atenuar ou abolir o papel da manualidade e da subjetividade no fazer artístico. Esses artistas, distanciando-se de parâmetros românticos, tais como originalidade e expressividade, absorveram técnicas e materiais relacionados com o modo de produção industrial, cujo princípio é o da divisão entre projeto e execução. No caso de Manuela, todavia, a coleta e a manipulação de silhuetas, bem como o emprego do estêncil e da pulverização, contribuíram não apenas para um afastamento do modo de produção artesanal de imagens, caraterizado pela "proeminência com que a fisicalidade dos suportes, substâncias e instrumentos utilizados impõem a sua presença" (SANTAELLA; NÖTH, 1998, p. 163), mas também para a constituição de uma visualidade particular. 
Na tela Louva-a-deus (Figura 2), por exemplo, silhuetas de figuras femininas em poses voluptuosas constituem e mesclam-se com a silhueta de um inseto, como sugere o título. Cabeças, braços, seios e pernas metamorfoseiam-se em ocelos, olhos compostos, palpos e mandíbulas. Esse convívio entre o humano e o animal pode ser associado, a despeito da distância histórica, aos chamados "grotescos", afrescos que decoram as ruínas da Domus Aurea de Nero, palácio descoberto em escavações realizadas na cidade de Roma em 1480 (KAYSER, 1986). Nesse gênero de pintura ornamental, considerada "licenciosa e muito ridícula" por autores como Giorgio Vasari (2011, p. 55), os artistas dispunham de liberdade suficiente para conferir "a cavalos patas feitas de folhas de árvores, a homem, pernas de grou, além de inúmeros outros disparates e despropósitos". No quadro de Manuela, o resultado também é a efígie de um corpo no qual as fronteiras anatômicas e as identidades fixas foram suplantadas.

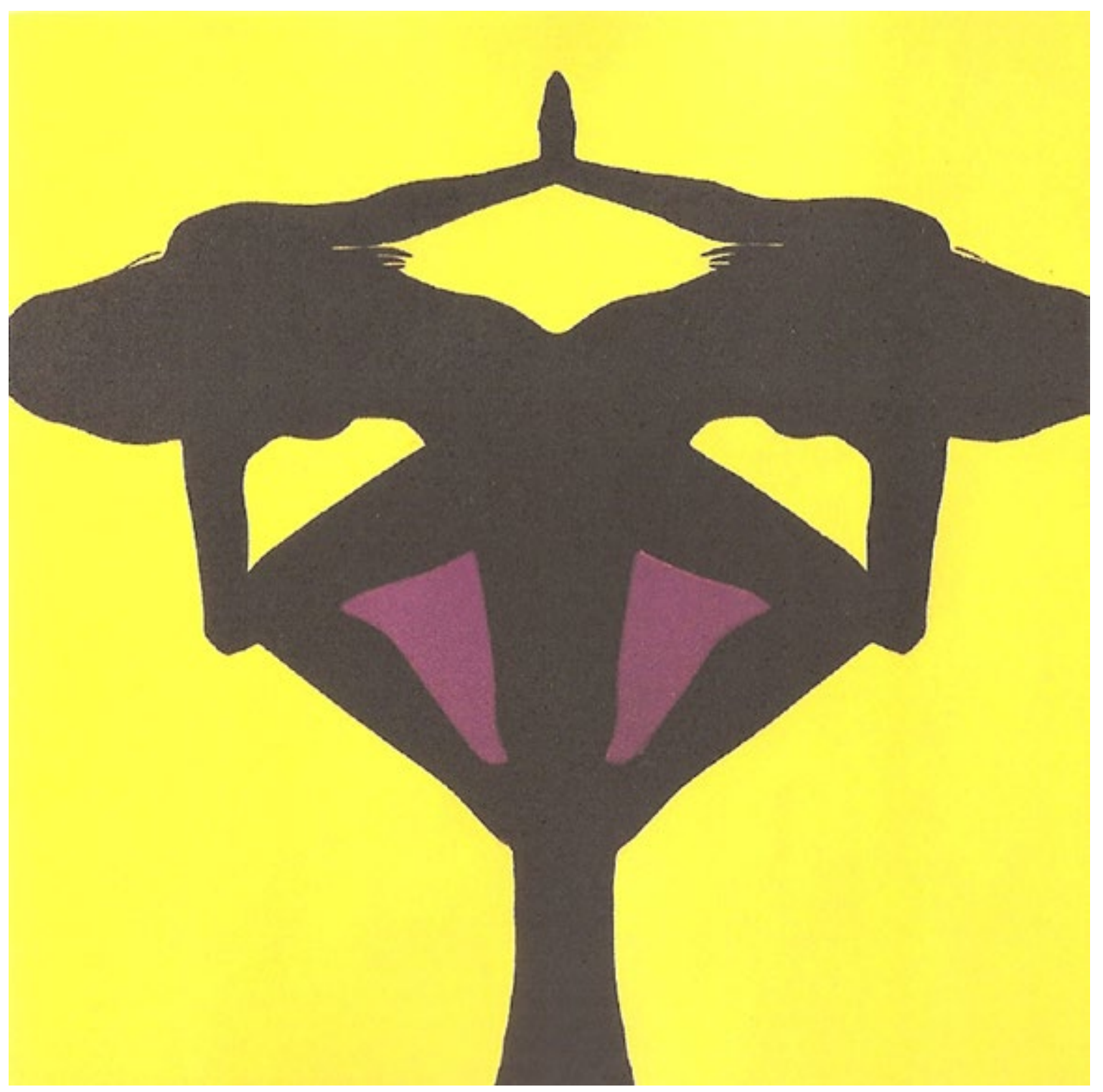

Fig. 2. Manuela Siebert, Louva-a-deus, 2015, acrílica sobre tela, $135 \times 135 \mathrm{~cm}$. Fonte: Acervo da artista. 
O amálgama de representações obtido por Manuela remonta ainda ao popular teste psicológico de Hermann Rorschach (1884-1922) e suas manchas simétricas. Desenvolvido entre 1911 e 1921, data em que o psiquiatra suíço publicou a sua monografia Psychodiagnostik e apresentou dez pranchas com borrões padronizados, o teste voltava-se para a avaliação da personalidade e seus dinamismos, baseandose, para tanto, no mecanismo da projeção. Acidentais e abstratas, as manchas de tinta usadas no teste, dada a sua ambiguidade estrutural, estão sujeitas a um grande número de interpretações, dependendo do estado de espírito do observador (GOMBRICH, 2007). Ao simular configurações semelhantes àquelas conseguidas por Rorschach, acrescentando-lhes silhuetas femininas identificáveis, pinturas como Tomara que caia (Figura 3) estabelecem um contraponto entre a figuração e a abstração, entre o calculado e o espontâneo.

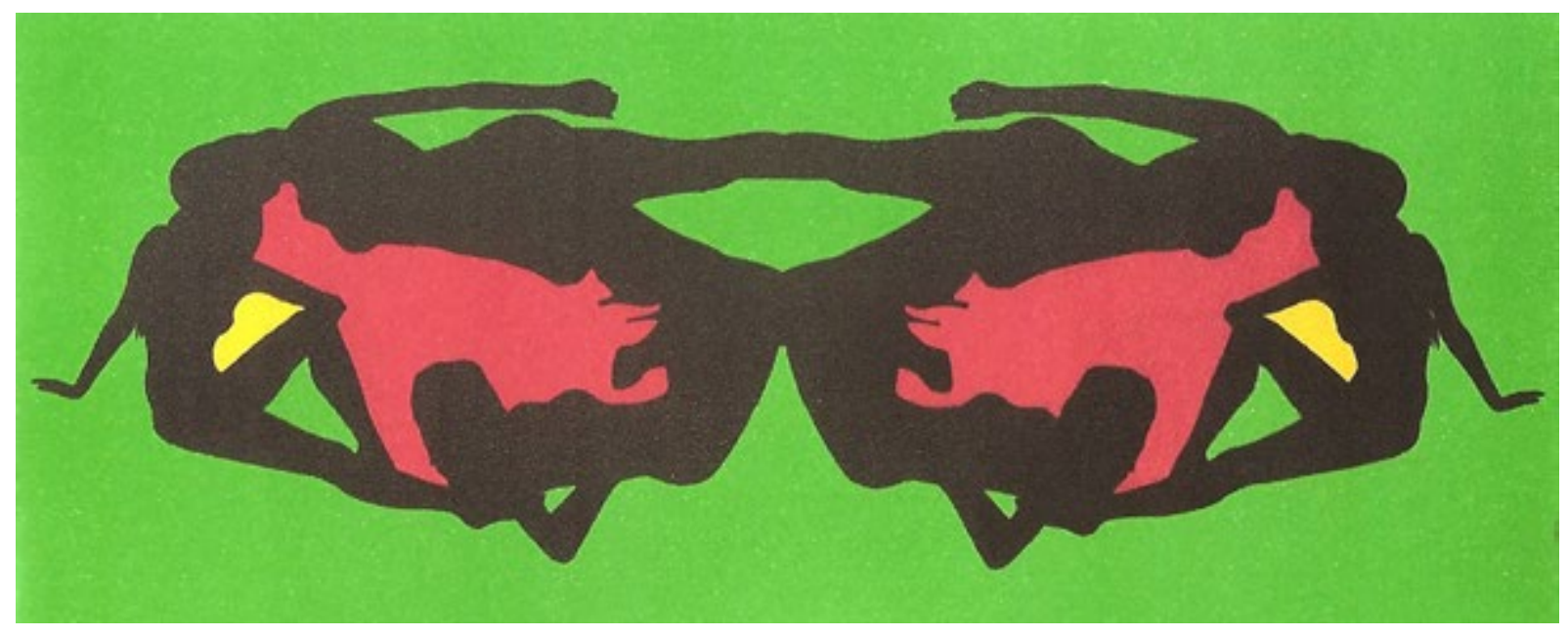

Fig. 3. Manuela Siebert, Tomara que caia, 2015, acrílica sobre tela, $80 \times 200 \mathrm{~cm}$.

Fonte: Acervo da artista.

Baseadas nas manchas de Rorschach, telas como Louva-a-deus e Tomara que caia foram organizadas por meio da simetria e da centralização, o que conferiu uma ordem rígida e maquinal aos trabalhos, frequentes no design gráfico e no design industrial. De efeito semelhante, mas seguindo outra solução compositiva, a pintura intitulada Centopeia em vermelho e preto (Figura 4) mostra uma silhueta feminina de salto alto que foi invertida alternadamente e encadeada horizontalmente por toda a superfície de um suporte de oitenta centímetros de altura por duzentos centímetros de largura. Aqui, a artista colocou-se entre o all-over pictórico - "superfície composta de elementos idênticos ou muito semelhantes que se repetem sem uma variação marcada de uma borda a outra da pintura" (GREENBERG, 1996, p. 165) - e as estampas mecanicamente impressas do papel de parede industrial. Como na produção de Andy Warhol, a simetria, a centralização e a repetição de imagens garantem um aspecto impessoal às pinturas de Manuela. 


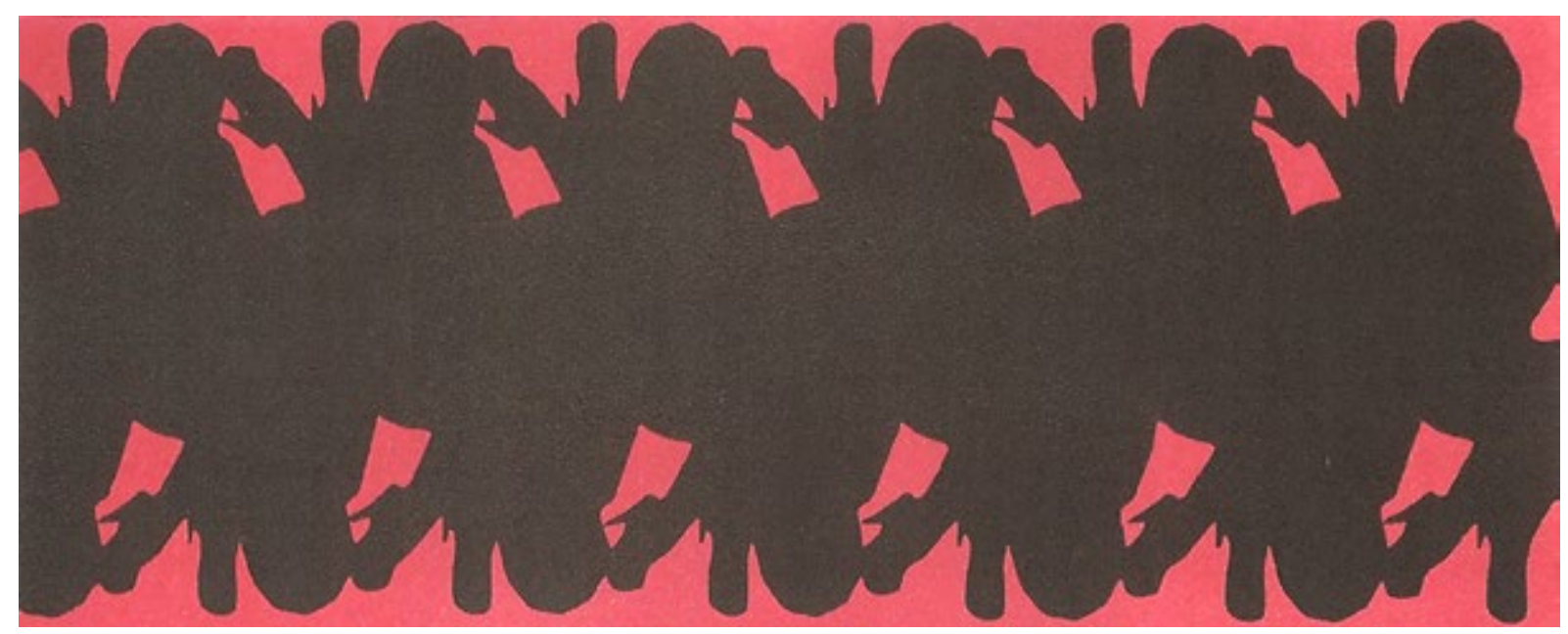

Fig. 4. Manuela Siebert, Centopeia em vermelho e preto, 2015, acrílica sobre tela, 80 × $200 \mathrm{~cm}$. Fonte: Acervo da artista.

Nessa operação de composição dos quadros, percebe-se a preocupação com a autonomia do campo visual, visto que Manuela adotou a técnica da pintura sobre tela e considerou os limites do meio. Entretanto, os trabalhos manifestam certo desconforto em relação a essa tradição, sobretudo no emprego da cor. Na tela Tomara que caia 2 (Figura 5), por exemplo, cores homogêneas e saturadas, ao mesmo tempo que obedecem a uma determinação interna, promovendo uma relação ambígua entre figura e fundo, remetem com insistência ao colorido das embalagens de produtos que ocupam as prateleiras de lojas de cosméticos, de $\mathrm{R} \$ 1,99$ e de supermercados. $A$ artista, afastando-se deliberadamente dos matizes rebaixados usualmente associados à pintura de cavalete, obtidos muitas vezes por meio de misturas laboriosas, elegeu como paleta cores oferecidas de antemão por programas de edição de imagens e por cartelas disponíveis em lojas de tintas. As cores de Manuela são cores ready-made.

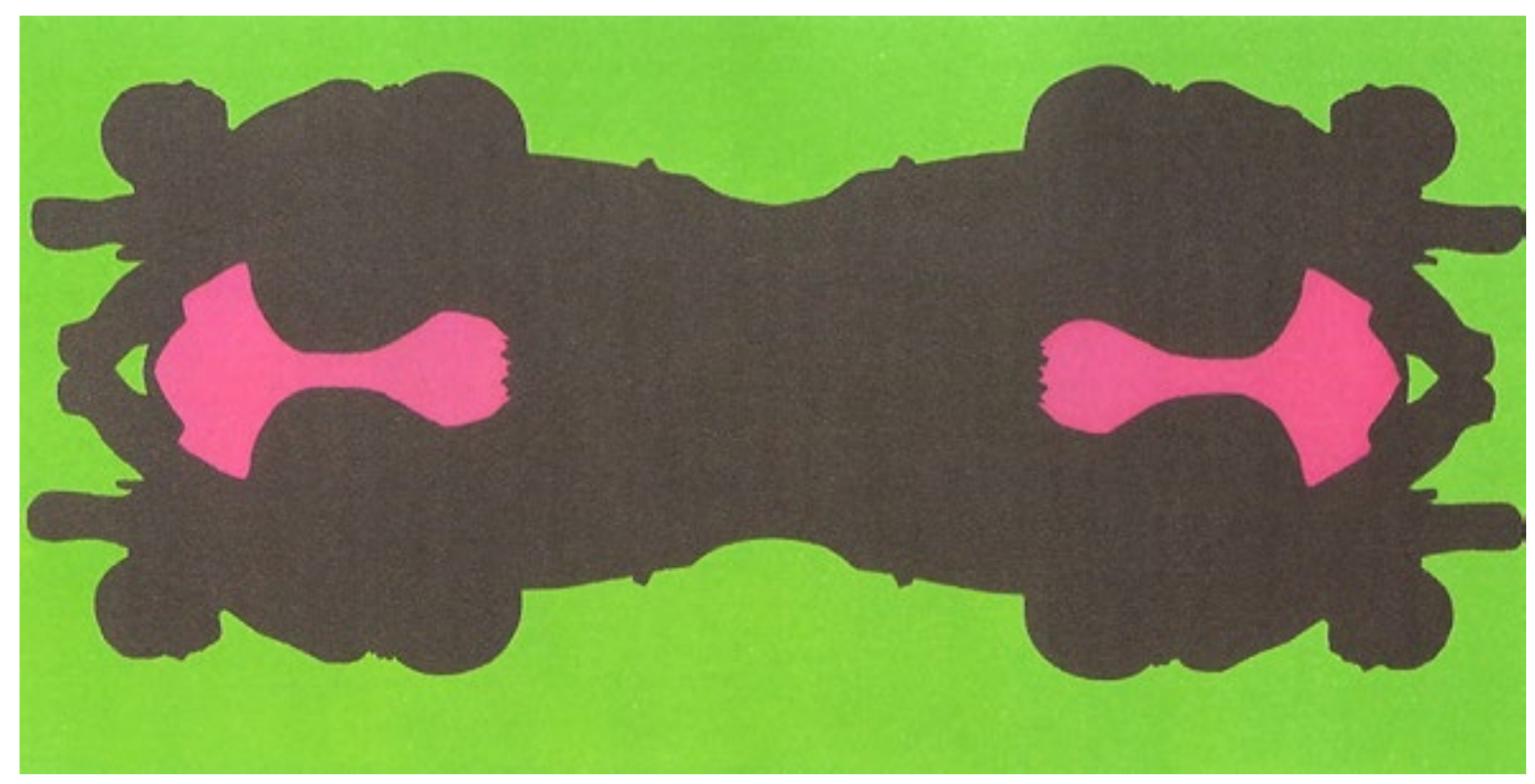

Fig. 5. Manuela Siebert, Tomara que caia 2, 2015, acrílica sobre tela, 100 × $200 \mathrm{~cm}$.

Fonte: Acervo da artista. 
Desse modo, em Tomara que caia 2, assim como nas demais pinturas que compõem a série Silhuetas e Fantasmagorias, é possível encontrar, junto ao fascínio pelo grotesco, uma visualidade de contornos duros e cores padronizadas, análoga àquela existente em placas de sinalização e em anúncios publicitários. Logo, os elementos utilizados pela artista catarinense na constituição de seus trabalhos, como as silhuetas recolhidas em sites de busca da Web e os matizes selecionados em programas de edição de imagens, embora deslocados de seu uso cotidiano, permanecem carregando aspectos ligados à sua origem no design e na comunicação visual. Como as pinturas feitas por Manuela no ano de 2012, as telas da série Silhuetas e Fantasmagorias situam-se entre as imagens da história da arte as imagens dos meios de comunicação de massa.

\section{Considerações finais}

Desde a sua invenção, a fotografia, considerada a primeira imagem técnica, impactou decisivamente os artistas e as artes ao ofuscar a primazia do artesanal e ao destacar o papel dos aparelhos como produtores de imagens. Ao longo de sua trajetória, Marcel Duchamp, por exemplo, retirou da fotografia possibilidades singulares de renovação de seus processos artísticos. Com o surgimento do readymade, que não deixa de apresentar semelhanças com o princípio fotográfico, a habilidade técnica do artista deixou de ser uma condição essencial para a produção de um trabalho de arte. A imagem técnica e seus atributos também estão na base da poética de Andy Warhol e dos "apropriacionistas" da década de 1980. Assumindo uma postura niveladora, ambos contrariaram a separação categórica, formulada pela teoria modernista da arte, entre a "arte" e a "cultura", entre o artesanal e o mecânico.

Do mesmo modo, a artista catarinense Manuela Siebert, ao eleger técnicas e materiais associados ao universo do design e da comunicação visual, buscou reduzir - papel da manualidade na constituição das pinturas que integram a série Silhuetas e Fantasmagorias. Nesse caso, a execução dos trabalhos foi racionalizada e fracionada em etapas sucessivas: manipulação digital de imagens já existentes, confecção de estênceis a partir das imagens retrabalhadas e, por fim, pulverização com uma pistola de ar comprimido. Todo esse processo relaciona-se com uma incorporação do modo de produção industrial e também do modo de produção das imagens técnicas. No final, as pinturas da série apresentam, ao lado da atração pelo fantasmagórico, uma superfície impessoal e uniforme, muito próxima daquela encontrada nas imagens veiculadas pelos meios de comunicação de massa.

Ao atenuar a contradição entre o artesanal e o mecânico, os trabalhos de Manuela confirmam a mudança de posição da pintura. Hoje, a prática pictórica ocorre em um contexto de circulação sem precedentes de imagens produzidas por aparelhos, refratário à tradicional hierarquia entre as chamadas "cultura erudita" e "cultura de massa", bem como entre as artes visuais e as artes aplicadas. As imagens, 
nessa situação, migram euforicamente de um meio a outro, de uma natureza à outra, do fotográfico ao digital, do digital ao pictórico ou ao contrário. Nesse cenário, as relações entre os diferentes meios, como exemplificado pelos modos operativos de Manuela e de outros artistas contemporâneos, não são de exclusão ou subordinação, mas de comércio recíproco.

\section{Referências}

ADES, Dawn. Fotomontaje. Barcelona: Editorial Gustavo Gili, 2002.

ARGAN, Giulio Carlo. Arte moderna: do lluminismo aos movimentos contemporâneos. São Paulo: Companhia das Letras, 1992.

BENJAMIN, Walter. Origem do drama barroco alemão. São Paulo: Brasiliense, 1984.

CABANNE, Pierre. Marcel Duchamp: engenheiro do tempo perdido. São Paulo: Perspectiva, 2002.

COWAN, Michael. The Ambivalence of Ornament: Silhouette Advertisements in Print and Film in Early Twentieth-Century Germany. Art History, vol. 36, n. 4, p. 784-809, September 2013.

FABRIS, Annateresa. A "pós-imagem mecanizada": fotografia e arte pop. In:

Fotografia e arredores. Florianópolis: Letras Contemporâneas, 2009. p. 142-148.

O debate crítico sobre o Hiper-realismo. ArtCultura, Uberlândia, v. 15, n. 27, p. 233-244, jul./dez. 2013.

FLORES, Laura González. Fotografia e pintura: dois meios diferentes? São Paulo: Editora WMF Martins Fontes, 2011.

FLUSSER, Vilém. Filosofia da caixa preta: ensaios para uma futura filosofia da fotografia. São Paulo: Editora Hucitec, 1985.

GAGE, John. A cor na arte. São Paulo: WMF Martins Fontes, 2012.

GOMBRICH, Ernst Hans. Arte e ilusão: um estudo da psicologia da representação pictórica. São Paulo: WMF Martins Fontes, 2007.

GREENBERG, Clement. A crise da pintura de cavalete. In: Arte e cultura. São Paulo: Ática, 1996. p. 164-167.

KAYSER, Wolfgang Johannes. O grotesco: configuração na pintura e na literatura. São Paulo: Perspectiva, 1986. 
KRAUSS, Rosalind. Marcel Duchamp ou o campo imaginário. In: . O fotográfico. Barcelona: Editorial Gustavo Gili, 2013. p. 76-93.

LARA, Arthur Hunold. Grafite: arte urbana em movimento. 1996. 130 f. Dissertação (Mestrado em Ciências da Comunicação) - ECA, Universidade de São Paulo, São Paulo, 1996.

OWENS, Craig. O impulso alegórico: sobre uma teoria do pós-modernismo. Arte \& Ensaios, Revista da Pós-Graduação em Artes Visuais da Escola de Belas Artes/UFRJ, Rio de Janeiro, ano XI, n. 11, p. 113-125, 2004.

ROSENBERG, Harold. Os action painters norte-americanos. In: A tradição do novo. Perspectiva: São Paulo, 1974. p. 11-22.

SANTAELLA, Lucia; NÖTH, Winfred. Imagem: cognição, semiótica, mídia. São Paulo: Editora Iluminuras Ltda, 1998.

SIEBERT, Manuela. Silhuetas e Fantasmagorias: entre pintura e imagem técnica. 2015. $139 \mathrm{f}$. Trabalho de Conclusão de Curso (Graduação) - Universidade do Estado de Santa Catarina, Santa Catarina, 2015.

STEINBERG, Leo. Jasper Johns: os sete primeiros anos de sua arte. In: Outros critérios: confrontos com a arte do século XX. São Paulo: Cosac Naify, 2008. p. 39-78. VASARI, Giorgio. Vidas dos artistas. São Paulo: Editora WMF Martins Fontes, 2011. 